\title{
UCRL-CONF-203300
}

LA WPENCE LIVEAMCAE NATIONAL LABOAATOAY

\section{Testing LaMgAl11019 crystal for X-ray spectroscopy}

H. Chen, P. Beiersdorfer, E. O. Baronova, I.I. Kalashnikova, M. M. Stepanenko

March 31, 2004

Submitted to 15th HTPD Conference

San Diego, CA, April 19, 2004 - April 22, 2004 
This document was prepared as an account of work sponsored by an agency of the United States Government. Neither the United States Government nor the University of California nor any of their employees, makes any warranty, express or implied, or assumes any legal liability or responsibility for the accuracy, completeness, or usefulness of any information, apparatus, product, or process disclosed, or represents that its use would not infringe privately owned rights. Reference herein to any specific commercial product, process, or service by trade name, trademark, manufacturer, or otherwise, does not necessarily constitute or imply its endorsement, recommendation, or favoring by the United States Government or the University of California. The views and opinions of authors expressed herein do not necessarily state or reflect those of the United States Government or the University of California, and shall not be used for advertising or product endorsement purposes.

This work was performed under the auspices of the U.S. Department of Energy by University of California, Lawrence Livermore National Laboratory under Contract W-7405-Eng-48 


\title{
Testing $\mathrm{LaMgAl}{ }_{11} \mathrm{O}_{19}$ crystal for X-ray spectroscopy
}

\author{
H. Chen, P. Beiersdorfer \\ Lawrence Livermore National Laboratory, Livermore, CA 94550-9234, U.S.A. \\ E. O. Baronova, I.I. Kalashnikova, M. M. Stepanenko \\ RRC Kurchatov Institute, Moscow, Russia
}

(March 31, 2004)

\begin{abstract}
We investigated the properties of the rare earth crystal $\mathrm{LaMgAl}_{11} \mathrm{O}_{19}$ and its application to soft $\mathrm{X}$-ray spectroscopy. Its relative reflectivity and half width rocking curve were measured to up to the reflection order of 28 . In addition, a comparative measurement of the iron L-shell soft X-ray line emission was made on the EBIT-I Livermore electron beam ion trap by fielding the $\mathrm{LaMgAl} \mathrm{I}_{11} \mathrm{O}_{19}$ crystal side by side with a rubidium hydrogen phthalate crystal in a flat crystal spectrometer. From these measurements, reflectivity and spectral resolving power were determined.
\end{abstract}

Typeset using REVTEX 


\section{INTRODUCTION}

Crystals are extensively used in soft X-ray spectroscopy in many fields of plasma physics including laboratory fusion and astrophysics. Many comprehensive articles on crystals are available. Excellent review articles by Burek [1] and by Alexandropoulos and Cohen [2] (together with the references cited within) have discussed a large number of commonly used crystals for X-ray measurements. Another important paper is by Henke, Gullikson and Davis [3]. In this paper, the reflection characteristics are tabulated for many frequently used crystals.

Each crystal has its own unique properties that benefit certain measurements and therefore exploring the usage of new crystals is an important and interesting task. $\mathrm{LaMgAl}_{11} \mathrm{O}_{19}$ crystal is such a new crystal. With interplanar atomic spacing of 22 angstroms, it can be a good candidate in spectroscopic measurement of L-shell emissions of many intermediate elements. Although the chemical composition of $\mathrm{LaMgAl}_{11} \mathrm{O}_{19}$ crystal was known for decades, its reflection property is not readily available from existing references.

$\mathrm{LaMgAl}_{11} \mathrm{O}_{19}$ is rare earth aluminate belonging to a family that shares a general formula $\mathrm{LaMgAl}_{11} \mathrm{O}_{19}$, with elements $\mathrm{La}, \mathrm{Pr}, \mathrm{Nd}, \mathrm{Sm}, \mathrm{Eu}, \mathrm{Gd}$ in the place of $\mathrm{La}^{3+}$ and $\mathrm{Mg}, \mathrm{Ni}$, $\mathrm{Co}, \mathrm{Mn}, \mathrm{Fe}$ in the place of $\mathrm{Mg}^{2+}$ [4]. These crystals have structure type similar to that of magnetoplumbite $\mathrm{PbFe}_{12} \mathrm{O}_{19}$, in which $\mathrm{Al}^{+3}$ substitutes for $\mathrm{Fe}^{3+}, \mathrm{La}^{3+}$ substitutes for $\mathrm{Pb}^{2+}$, and $\mathrm{Mg}^{2+}$ substitutes for $\mathrm{Fe}^{3+}$. The chemical features of aluminate crystals, including those of $\mathrm{LaMgAl}_{11} \mathrm{O}_{19}$, have been studied in [4] [5]. The main interest in these crystals was their use as laser materials. In this paper, we study the properties of the $\mathrm{LaMgAl}_{11} \mathrm{O}_{19}$ crystal for x-ray spectroscopic applications.

\section{RELATIVE REFLECTIVITY AND ROCKING CURVE}

The $\mathrm{LaMgAl}_{11} \mathrm{O}_{19}$ crystal we evaluated was grown at the RRC Kurchatov Institute at Moscow, Russia. The crystal boule was grown along the $\mathrm{X}$-axis using the Chohralsky ap- 
proach. The flat crystal was manufactured with the mechanical plane parallel to plane 0001 (Z plane). Space group of symmetry is $\mathrm{P} 6_{3} \mathrm{mmm}$ with parameters of $\mathrm{a}=\mathrm{b}=5.58 \AA, \mathrm{c}=22.00$ $\AA$. Being a hexagonal crystal, $\mathrm{LaMgAl}_{11} \mathrm{O}_{19}$ can be used as a polarimeter for x-ray line polarization measurement [6]. The crystal was sized $(107 \mathrm{~mm} \times 10 \mathrm{~mm} \times 2 \mathrm{~mm})$ to fit into the dual-crystal flat field spectrometer [7] at the Livermore electron beam ion trap laboratory in USA.

Laboratory measurements carried out at the Kurchatov Institute have yielded a set of characteristic parameters for the $\mathrm{LaMgAl}_{11} \mathrm{O}_{19}$ crystal including the relative reflectivity and the half width rocking curve (HWRC). The relative reflectivity was measured in the central part of the crystal using the $\mathrm{Cu} \mathrm{K}_{\alpha 1}$ line in second through twenty-four order of reflection. The measurement was made with a diffractometer operating at a voltage of $25 \mathrm{kV}$ and a current of $19 \mathrm{~mA}$. The $\mathrm{Cu} \mathrm{K} \beta$ line was used for $\mathrm{n}=28$ order of reflection. Table I gives the measured peak intensities (relative units) and HWRC measured in the central part of the crystal for various orders of reflection. The HWRC was obtained under the condition where the spectrometer was fixed in position $(2 \theta=$ constant $)$ while the position of the crystal was varied $(\theta \neq$ constant $)$. The resolution of our apparatus was $2.5 \operatorname{arcsec}$. The value of the apparatus function was determined by the distance between anode and crystal and by the size of slit $(0.1 \mathrm{~mm}$ in width and $4 \mathrm{~mm}$ in height). Parameter $\mathrm{c}=22.04 \AA$ was calculated from Bragg's law and the measured reflection angles in different orders.

We made a detailed measurement of the HWRC and $\theta$ and $2 \theta$ as a function of position along the crystal (stepsize $5 \mathrm{~mm}$ ) at reflection order $\mathrm{n}=8$. The results are given in Table II.

\section{FIRST ORDER REFLECTIVITY RELATIVE TO RAP CRYSTAL}

By fielding the $\mathrm{LaMgAl}_{11} \mathrm{O}_{19}$ crystal side by side with an RAP crystal on a dual-crystal flat field spectrometer [7] [8], we determined the relative reflectivity of $\mathrm{LaMg}_{11} \mathrm{O}_{19}$ crystal using the Livermore EBIT-I electron beam ion trap [9]. Figure 1 is a schematic diagram of the spectrometer setup. The RAP crystal has a size of $120 \mathrm{~mm} \times 12 \mathrm{~mm} \times 2 \mathrm{~mm}$. Position 
sensitive gas proportional counters were used as detectors.

We choose RAP (rubidium hydrogen phthalate) as the reference crystal because it has relative high reflectivity and spectral resolving power. Also, it has a $2 d$ spacing $(2 d=26.121$ $\AA)$ close to that of the $\mathrm{LaMgAl}_{11} \mathrm{O}_{19}$ crystal $(2 d=22.04 \AA)$, and this allows the two crystals to cover the same wavelength range at a similar Bragg angle. Properties of RAP crystals can be found in many references including [1] and [3].

We measured the Fe L-shell x-ray line emission on EBIT-I using first order of reflection. EBIT-I has a magnetic field strength of $3 \mathrm{~T}$, which was provided by superconducting magnets; this field was needed to squeeze the diameter of an electron beam to about $50-60 \mu \mathrm{m}$, which served as the slit for the spectrometer. Iron was introduced in gas form $\left(\mathrm{Fe}(\mathrm{CO})_{5}\right)$ continuously into the trap via a bleed valve. Typical injection reservoir pressures were in the $10^{-8}$ to $10^{-7}$ Torr range while the pressure inside EBIT remains lower than $10^{-10}$ Torr. The gas proportional counter detector was filled with 1 atmosphere pressure of $\mathrm{P}-10\left(10 \% \mathrm{CH}_{4}\right.$ and $90 \%$ Ar) gas.

The RAP crystal was set to a 25.5 degree Bragg angle, giving a wavelength coverage from $9.7 \AA$ to $12.6 \AA(1.0-1.3 \mathrm{keV})$. An integration time of 20 minutes gave the Fe L-shell spectrum shown in Fig. 2. For the $\mathrm{LaMgAl}_{11} \mathrm{O}_{19}$ crystal, the Bragg angle was set to 32 degree, corresponding to a wavelength coverage from $10.9 \AA$ to $13.6 \AA(0.9-1.2 \mathrm{keV})$. After an integration time of 150 minutes, we obtained the spectrum shown in Fig. 2. The electron beam was set to an energy of $2.7 \mathrm{keV}$ in both cases.

We derived the relative reflectivity of the $\mathrm{LaMgAl}_{11} \mathrm{O}_{19}$ crystal from the line intensities of the observed spectra, as listed in Table III and Fig 3. The weighted average of these data indicates it has $6.6 \%$ of reflectivity relative to the RAP crystal at a photon energy of about $1 \mathrm{keV}$. It is important to note, however, that unlike most crystals, the reflection of $\operatorname{LaMgAl}_{11} \mathrm{O}_{19}$ at higher orders $(\mathrm{n}=4,6,8$ and 10) stays constant at a level half that of first order. This can be very beneficial if one uses it at higher order for shorter wavelength spectral measurements.

From the measured spectra, we also obtain the full width half maximum (FWHM) of the 
spectral lines, which is a indication of the resolving power of the crystals. The full width half maximum of the spectral lines from $\mathrm{LaMgAl}_{11} \mathrm{O}_{19}$ crystal is about $0.024 \pm 0.007 \AA$, which correspond to a resolving power of 410 . For RAP it is about $0.026 \pm 0.005 \AA$, corresponding to a resolving power of about 390 . This indicates that the spectral resolutions from the two crystals are close. The difference may be merely due to the variation in the resolving power with Bragg angle (where $\lambda / \Delta \lambda \propto \tan \theta)$. In fact, the change in the angle-dependent resolving power between $\theta=25.5^{\circ}$ and $\theta=32^{\circ}$ is about $30 \%$, indicating that the RAP crystal may even have a slightly higher resolving power than the $\mathrm{LaMgAl}_{11} \mathrm{O}_{19}$ crystal. The nominal resolving power of the RAP crystal at $\theta=45^{\circ}$ inferred from our measurement at $25.5^{\circ}$ is 820 , which is the same as that quoted in the reference [1]. By contrast, we infer a nominal resolving power of 660 for $\mathrm{LaMgAl}_{11} \mathrm{O}_{19}$. By comparison, the nominal resolving power of our spectrometer is about 2000 [7], and thus adds little to the observed line width. Similarly, the ion temperature is sufficiently low $(\mathfrak{i} 1000 \mathrm{eV})$ and does not affect the measurements either.

\section{ACKNOWLEDGEMENT}

The work at the University of California Lawrence Livermore National Laboratory was performed under the auspices of the Department of Energy under Contract No. W-7405Eng-48. 


\section{TABLES}

TABLE I. Measurement results for $\mathrm{LaMgAl}_{11} \mathrm{O}_{19}$ crystal at different orders of reflection.

\begin{tabular}{cccc}
\hline \hline Order of reflection & $d$ & Relative Intensity & HWRC \\
& $(\AA)$ & arbitrary units & (arcmin) \\
\hline 2 & 11.03 & 100 & 4.5 \\
4 & 5.51 & 50 & 4 \\
6 & 3.68 & 50 & $3.5-3.75$ \\
8 & 2.76 & 50 & 4 \\
10 & 2.205 & 50 & 4 \\
12 & 1.836 & 6 & 4 \\
14 & 1.574 & 12 & 3.7 \\
16 & 1.376 & 2 & 3.5 \\
20 & 1.102 & 6 & 3.25 \\
22 & 1.002 & 3 & 3.25 \\
24 & 0.919 & 1 & 3.5 \\
\hline \hline
\end{tabular}


TABLE II. Detailed measurements of the half-width rocking curve along different points of the crystal for order $n=8$.

\begin{tabular}{|c|c|}
\hline Point & $\begin{array}{l}\text { HWRC } \\
\text { (arcmin) }\end{array}$ \\
\hline 1 & 3.75 \\
\hline 2 & 3.5 \\
\hline 3 & 3.75 \\
\hline 4 & 3.75 \\
\hline 5 & 3.75 \\
\hline 6 & 3.75 \\
\hline 7 & 3.5 \\
\hline 8 & 3.5 \\
\hline 9 & 3.75 \\
\hline 10 & 3.5 \\
\hline 11 & 3.5 \\
\hline 12 & 3.75 \\
\hline 13 & 3.5 \\
\hline 14 & 3.5 \\
\hline 15 & 3.75 \\
\hline 16 & 3.5 \\
\hline 17 & 3.37 \\
\hline
\end{tabular}

Distance between points is $5 \mathrm{~mm}$. 
TABLE III. Line intensity measured using the $\mathrm{LaMgAl}{ }_{11} \mathrm{O}_{19}$ crystal relative to the RAP crystal

\begin{tabular}{cccc}
\hline \hline Ions & wavelength & Energy & Relative Int. \\
& $(\AA)$ & $(\mathrm{keV})$ & $(\%)$ \\
\hline Fe XXI & 12.5 & 0.99 & $6.3(1.4)$ \\
Fe XXI & 12.382 & 1.00 & $6.5(1.1)$ \\
Fe XXI & 12.284 & 1.01 & $8.2(1.3)$ \\
Fe XXII & 11.932 & 1.04 & $7.3(0.6)$ \\
Fe XXII & 11.77 & 1.05 & $6.1(0.5)$ \\
Fe XXIII & 11.736 & 1.06 & $6.1(0.8)$ \\
\hline \hline
\end{tabular}




\section{REFERENCES}

[1] A. Burek, Space Instrumentation 2, 53 (1976)

[2] N. G. Alexandropoulos and G. G. Cohen App. Spectroscopy 28, 155 (1974)

[3] Henke, B. L., Gullikson, E. M., \& Davis, J. C. , At. Data Nucl. Data Tables, 54, 181 (1993) (data from this work can be found at www.cxro.lbl.gov)

[4] A.Kahn, A. M. Lejus, M.Madsac, J. Thery, D. Vivien and J. C. Bernier J. Appl. Phys. $\mathbf{5 2}, 6864(1981)$

[5] W. Schonwelski, F. Haberey, R. Lechebusch, M. Rosenberg and K. Sahl Zeitschrift Fur Kristallographie 172, 233 (1985)

[6] E. O. Baronova and M. M. Stepanenko Plasma Phys. Control. Fusion, 45, 1113 (2003)

[7] P. Beiersdorfer and B. J. Wargelin 65, 13 (1994)

[8] Brown, G. V., Beiersdorfer, P., \& Widmann, K. Rev. Sci. Instrum., 70, 280 (1999)

[9] M. A. Levine, R. E. Marrs, J. R. Henderson, D. A. Knapp and M. B. Schneider, Physica Scripta, T22 157 (1988) 


\section{Figure Captions}

Fig 1. Schematic diagram of the dual-crystal spectrometer on EBIT-I.

Fig 2. Fe L-shell spectra taken using the $\mathrm{LaMgAl}_{11} \mathrm{O}_{19}$ and RAP crystals at an electron beam energy of $2.7 \mathrm{keV}$. The data acquisition time was 150 minutes for the $\mathrm{LaMgAl}_{11} \mathrm{O}_{19}$ crystal, and 20 minutes for the RAP crystal.

Fig 3. Measured reflectivities of $\mathrm{LaMgAl}_{11} \mathrm{O}_{19}$ relative to $\mathrm{RAP}$ at $1 \mathrm{keV}$ photon energy. The dots with error bar are individual data points. The line and grey area are the weighted average and weighted error, respectively. 


\section{FIGURES}

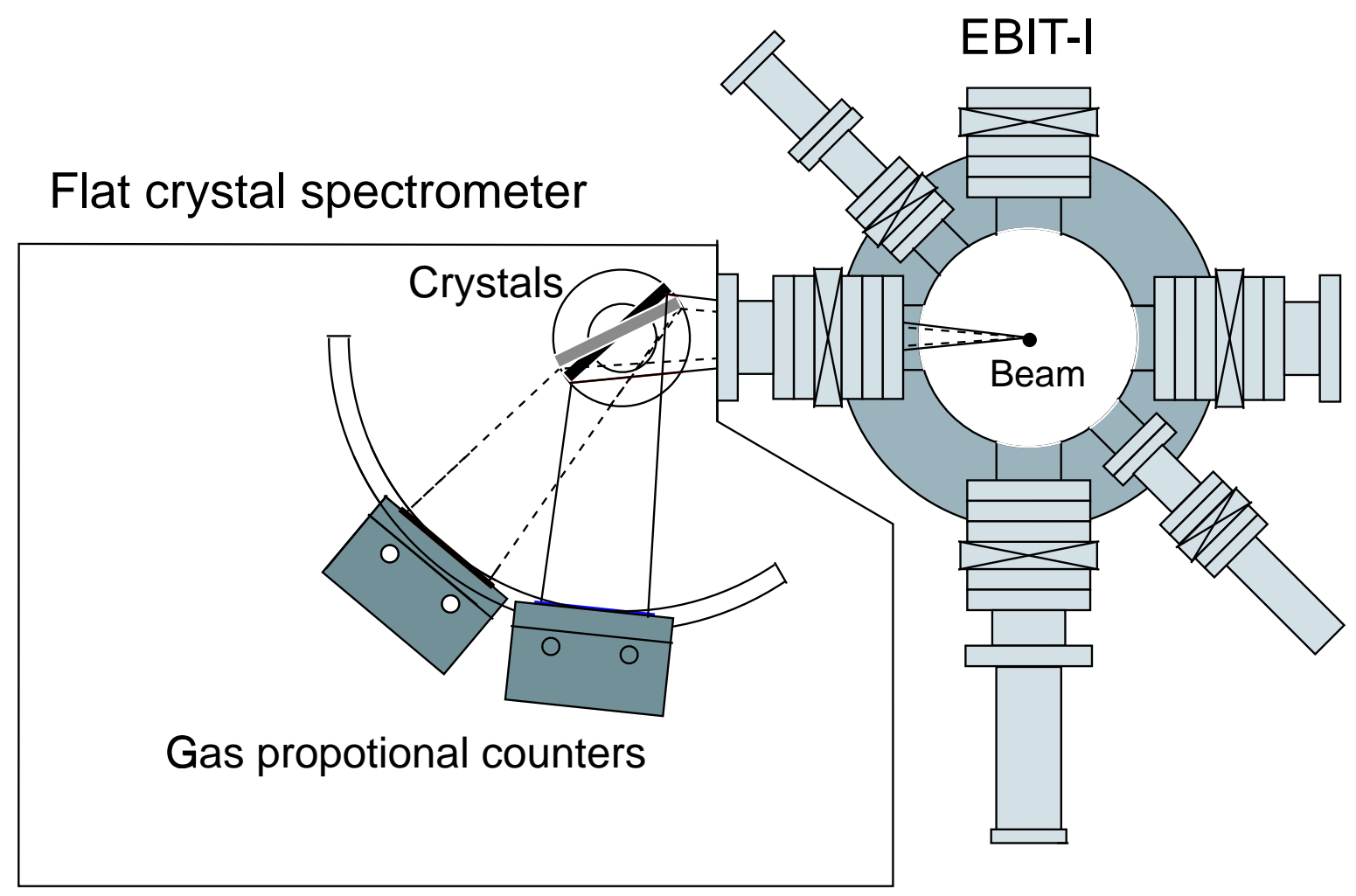

FIG. 1. 

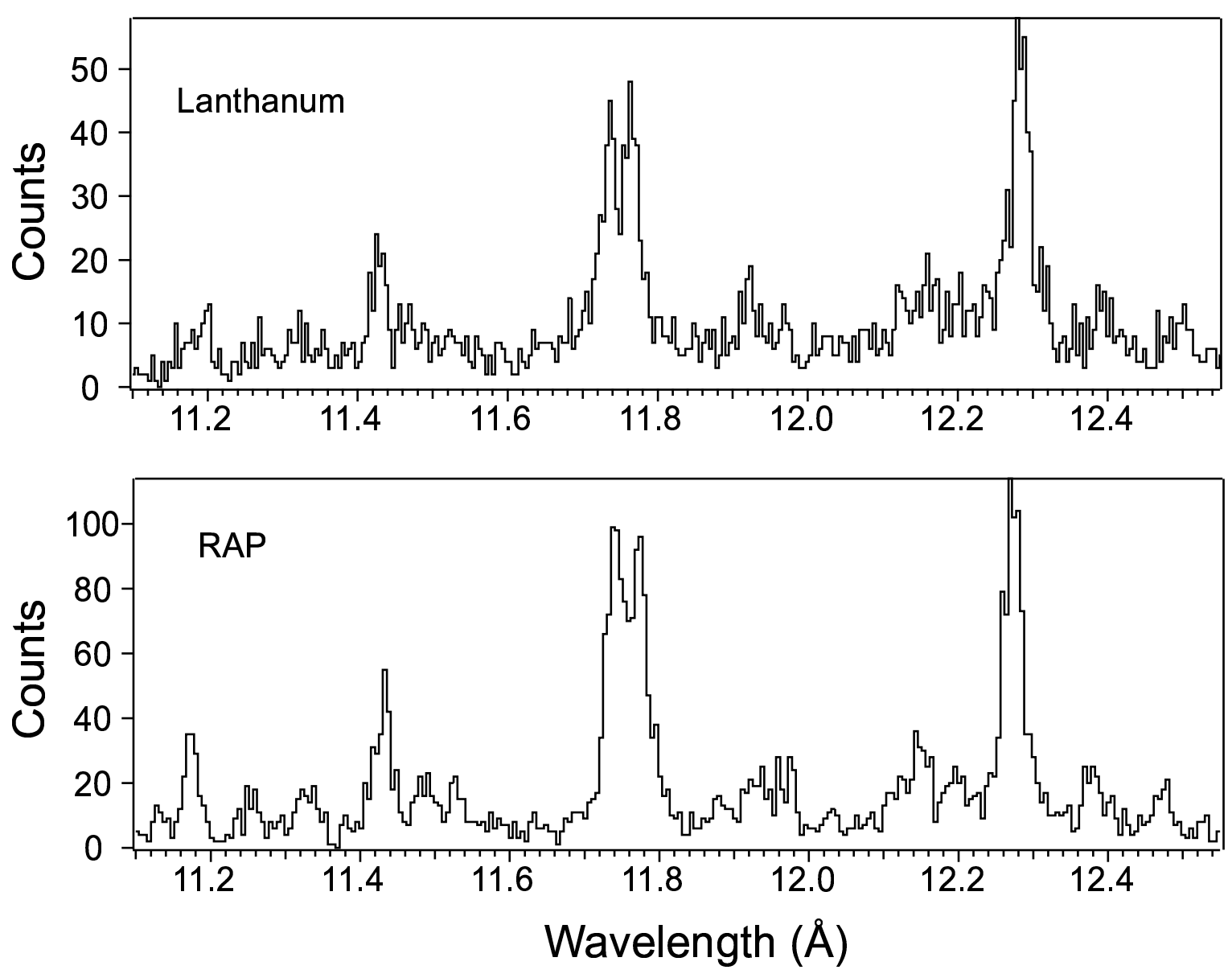

FIG. 2. 


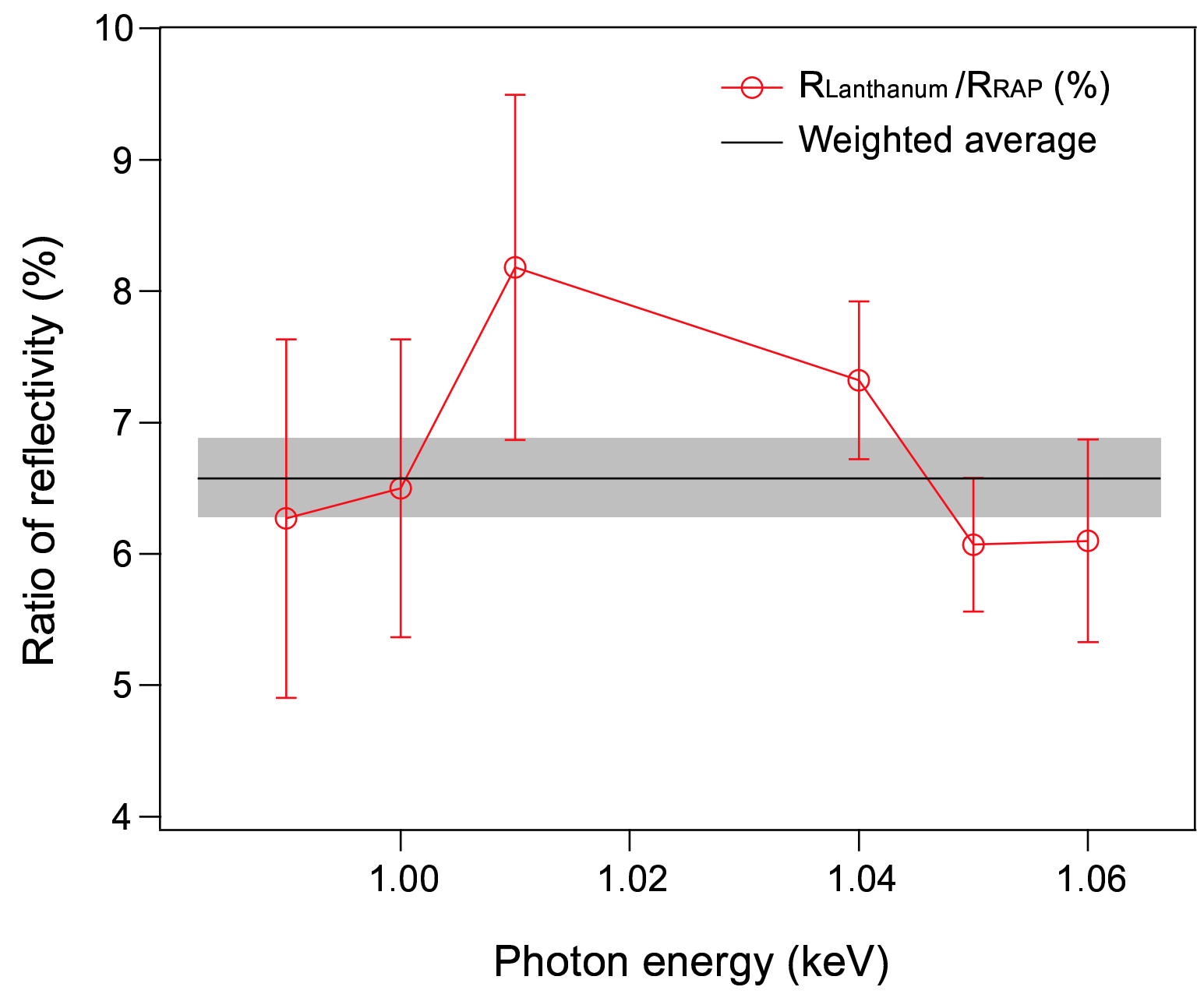

FIG. 3. 
University of California

Lawrence Livermore National Laboratory

Technical Information Department

Livermore, CA 94551

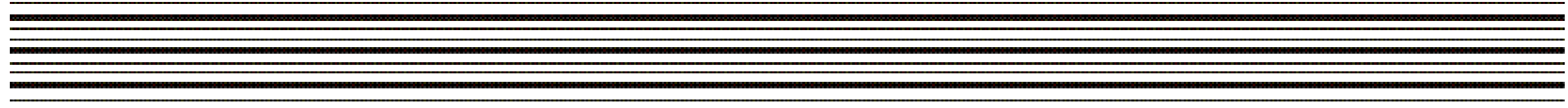

